\title{
Intraspecific crosses resulting in the first occurrence of eight and nine B chromosomes in Prochilodus lineatus (Characiformes, Prochilodontidae)
}

\author{
Tatiana Aparecida Voltolin ${ }^{1}$, José Augusto Senhorini ${ }^{2}$, Fausto Foresti ${ }^{3}$, Jehud Bortolozzi ${ }^{1}$ \\ and Fábio Porto-Foresti ${ }^{1}$ \\ ${ }^{1}$ Departamento Ciências Biológicas, Faculdade de Ciências, \\ Universidade Estadual Paulista “Júlio de Mesquita Filho”, Bauru, SP, Brazil. \\ ${ }^{2}$ Instituto Chico Mendes de Conservação da Biodiversidade, \\ Centro Nacional de Pesquisa e Conservação de Peixes Continentais, Pirassununga, SP, Brazil. \\ ${ }^{3}$ Departamento de Morfologia, Instituto de Biociências, \\ Universidade Estadual Paulista “Júlio de Mesquita Filho”, Botucatu, SP, Brazil.
}

\begin{abstract}
B chromosomes are supernumerary elements present in about 15\% of eukaryotic species and are most frequently heterochromatic, behave parasitically, show a transmission rate higher than standard (A) chromosomes, and can provoke harmful effects on carriers. In the current work, Prochilodus lineatus individuals carrying eight and nine B chromosomes were obtained by induced crossing performed involving breeders with different B chromosome numbers in their cells. The high B chromosome numbers found in the offspring were recorded for the first time in this species. The use of cytogenetic techniques applied in the present study revealed that regardless of the increase in number of B chromosomes in the genome of these individuals, those elements did not presented active genes, and showed their normal heterochromatic characteristic.
\end{abstract}

Key words: supernumerary chromosome, heterochromatic chromosome, cross-fertilization.

Received: August 17, 2010; Accepted: November 30, 2010.

\section{Introduction}

Prochilodus lineatus, a fish species of the family Prochilodontidae, is considered one of the most important components of commercial and subsistence fishery in freshwater environments in South America, with the exception of Chile, where this species is not found (LoweMcConnell, 1975; Goulding, 1981; Vari, 1983). Amongst all the species of this genus, $P$. lineatus, popularly known as curimbatá, is certainly the most-studied species so far in this region (Godoy, 1975). Furthermore, this species presents an optimal adaptation to growth and reproduction in captivity, thus becoming highly interesting for fish culture programs (Britski, 1972; Godoy, 1975; Castro, 1993).

The chromosomal organization of $P$. lineatus has been described in previous cytogenetic studies (Pauls and Bertollo, 1983, 1990; Oliveira et al., 1997; Cavallaro et al., 2000; Jesus and Moreira-Filho, 2003; Artoni et al., 2006; Vicari et al., 2006; Voltolin et al., 2009). The karyotype of this species consists of 54 meta/submetacentric chromo-

Send correspondence to Fabio Porto-Foresti. Laboratório de Genética de Peixes, Departamento Ciências Biológicas, Faculdade de Ciências, Universidade Estadual Paulista "Júlio de Mesquita Filho", Campus de Bauru, Av. Engenheiro Luiz Edmundo C. Coube s/n, 17033-360 Bauru, SP, Brazil. E-mail: fpforesti@fc.unesp.br. somes and may present from zero to seven B microchromosomes that vary between and also within populations (Jesus and Moreira-Filho, 2003).

A surprisingly diverse occurrence of B chromosomes in Neotropical fishes is found among representatives of the order Characiformes, where this extra-genomic element has been found in 31 species in six distinct families: Anostomidae, Characidae, Crenuchidae, Curimatidae, Parodontidae, and Prochilodontidae (Carvalho et al., 2008), which represent $50.82 \%$ of all the species carrying B chromosomes. They show a considerable variability in relation to size, morphology, and number.

Based on the occurrence of different frequencies of supernumerary chromosomes already reported in $P$. lineatus, our purpose in this study was to contribute to the knowledge about frequency variation in filial generations and its maintenance in individuals obtained from oriented crosses carried out in individuals maintained at the CEPTA/ICMBio, Pirassununga, SP, Brazil.

\section{Material and Methods}

41 individuals of the $P$. lineatus species (three parents - one male and two females - and 38 individuals representing the two filial generations) were cytogenetically ana- 
lyzed. In the cross-fertilization carried out in the CEPTA/ICMBio facilities, three parents captured from the natural population of the Mogi-Guaçu River, Pirassununga, SP, Brazil, were used. The single male was simultaneously crossed with two females, originating two filial generations by cross-fertilization were. The filial generation A composed of 12 and filial generation B of 26 individuals.

Chromosome preparations from kidney tissue were obtained following the method of Foresti et al. (1993). For the establishment of the modal number of $\mathrm{B}$ chromosomes, 30 cells with $2 \mathrm{n}=54$ A chromosomes from each individual were analyzed. Nucleolar organizer regions (NOR) were identified on the chromosome complement using the silver nitrate staining technique developed by Howell and Black (1980), and constitutive heterochromatin patterns on chromosome preparations were obtained following the method of Sumner (1972).

\section{Results}

The karyotypic constitution of the three parents used in the cross-fertilization exhibited a diploid number of $2 \mathrm{n}=54$ chromosomes of metacentric and submetacentric types with a fundamental number equal to 108 , with interindividual variation in the presence of $\mathrm{B}$ chromosomes, the male having six B chromosomes; one of the females had four and the other five.

The two filial generations resulting from these two crosses (Figure 1a, b) showed no differences concerning diploid number, chromosome type, and fundamental number and all the 38 individuals comprising the progenies exhibited supernumerary chromosomes. Twelve individuals of filial generation A (Figure 1a), originating from the cross involving the male with six $\mathrm{B}$ chromosomes and the female with four B chromosomes, presented four individuals carrying three B $(30.7 \%)$, two individuals carrying four B (15.4\%); five individuals carrying six B (46.2\%), and finally, one individual carrying eight B chromosomes (Figure $2 \mathrm{a}$ ), corresponding to $7.7 \%$ of the total individuals analyzed. Among the 26 individuals of filial generation B

\begin{tabular}{|c|c|c|c|}
\hline & $6 \mathrm{~B} \hat{O}$ & $\mathrm{X}$ & \\
\hline $\begin{array}{l}3 \mathrm{~B} \\
30.7 \%\end{array}$ & $\begin{array}{l}4 \mathrm{~B} \\
15.4 \%\end{array}$ & $\begin{array}{c}6 \mathrm{~B} \\
46.2 \%\end{array}$ & $\begin{array}{c}8 \mathrm{~B} \\
7.7 \%\end{array}$ \\
\hline
\end{tabular}

\begin{tabular}{|cccccccc|}
\hline & $6 \mathrm{~B}$ & $\hat{\sigma}$ & $\mathrm{X}$ & \multicolumn{3}{c|}{$5 \mathrm{~B}$ 早 } \\
& & & & & & \\
$3 \mathrm{~B}$ & $4 \mathrm{~B}$ & $5 \mathrm{~B}$ & $6 \mathrm{~B}$ & $7 \mathrm{~B}$ & $8 \mathrm{~B}$ & $9 \mathrm{~B}$ \\
$7.6 \%$ & $11.7 \%$ & $50 \%$ & $15.5 \%$ & $3.8 \%$ & $7.6 \%$ & $3.8 \%$ \\
\hline$\hat{\sigma}=$ male & q $=$ female
\end{tabular}

Figure 1 - Proportions of B chromosomes present in the F1 generation resulting from induced crosses of the respective parental generation.
(Figure 1b), originating from the cross involving the male with six and the female with five $\mathrm{B}$ chromosomes, presented two individuals carrying three B (7.6\%); three individuals carrying four B (11.7\%); 13 individuals carrying five B (50\%); one individual with seven B (3.8\%); two individuals carrying eight $\mathrm{B}$ chromosomes (Figure 2a) (7.6\%), and finally, one individual carrying nine B chromosomes, representing $3.8 \%$ of the total (Figure $2 b$ ).

Aiming at a better cytogenetic characterization of the individuals carrying eight and nine B chromosomes, the technique for the detection of nucleolar organizer regions by silver nitrate impregnation was applied, revealing the characteristic labeling on the long arm of the third largest submetacentric chromosome pair of the karyotype in all individuals of $P$. lineatus analyzed (Figure 2c,d). Moreover, size polymorphism was detected involving this region in the homologous chromosomes.

Staining with the C-banding technique revealed conspicuous heterochromatic blocks in the centromeric regions

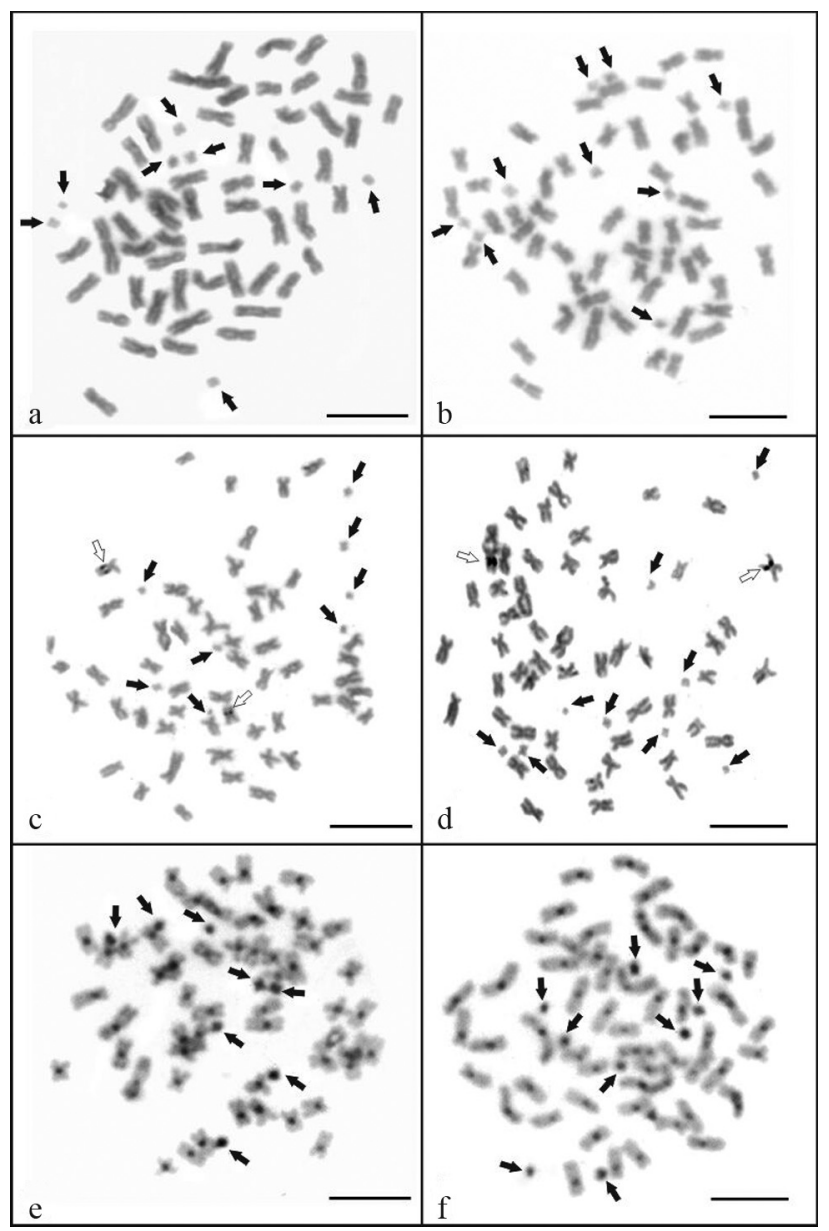

Figure 2 - Metaphases of Prochilodus lineatus showing the presence of eight (a) and nine (b) B chromosomes; metaphases showing the presence of the Nucleolar Organizer Region (NOR) in the chromosomes of individuals with eight (c) and nine (d) B chromosomes; and metaphases after $\mathrm{C}$-banding showing the presence of heterochromatic blocks in the chromosomes of individuals with eight (e) and nine (f) B chromosomes. Scale bars: $10 \mu \mathrm{m}$. 
of the chromosome complement and in the telomeric region of one chromosome pair. All the supernumerary chromosomes revealed to be completely or partially heterochromatic (Figure 2e,f).

\section{Discussion}

The genus Prochilodus (Prochilodontidae) exhibits a relatively conserved karyotypic structure with $2 \mathrm{n}=54$ metacentric and submetacentric chromosomes (Pauls and Bertollo, 1990; Fenocchio et al., 2003). However, some Prochilodus species show variation in chromosome number attributed to the occurrence of supernumerary or B chromosomes. Previous reports on the presence and number per cell of these genomic elements revealed that from zero to seven units can easily be identified as heterochromatic microchromosomes in this species (Pauls and Bertollo, 1983; Oliveira et al., 1997; Cavallaro et al., 2000).

Since their discovery at the beginning of the last century (Wilson, 1907), the maintenance of B chromosomes in nature has been thoroughly considered (Jones and Rees, 1982; Jones, 1995; Camacho et al., 2000; Puertas, 2002). The present work registered the presence of eight and nine B chromosomes in individuals of the filial generations of $P$. lineatus (Figure 2a,b) obtained by cross-fertilization. This new variation in the number of supernumerary chromosomes has not been observed previously in individuals of this species, either in nature or in fish culture.

Through induced reproduction in $P$. lineatus, it was ascertained that the $\mathrm{B}$ chromosome maintenance is associated with the number of supernumerary chromosomes present in the parental gametes. When large numbers of B chromosomes were present in the ancestors' haploid cells, the individuals originating from these crosses presented a considerable number of $\mathrm{B}$ chromosomes. In nature, the occurrence of eight and nine $\mathrm{B}$ chromosomes had not yet been registered, because finding individuals with a large number of microchromosomes in their genome is very rare, since the modal number for this species ranges from two to three extra elements (Voltolin et al., 2009). Moreover, it is most unlikely that gametes carrying a high number of B chromosomes would be found as a result of chance occurrences among the individuals of these natural populations. However, the obtaining of filial generations of $P$. lineatus in captivity demonstrated that these individuals are able to carry a great number of $\mathrm{B}$ in their genome.

The maximum number of $\mathrm{B}$ chromosomes that a species is capable of tolerating can measured by the maximum number of B chromosomes found in adult individuals in a population (Camacho et al., 2000). Any extra genomic element possessing an accumulation mechanism would be able to evolve into a B chromosome. Such a characteristic parasitic B would be rapidly increased in frequency to the point of becoming a burden to the host genome (Camacho et al., 2000). Some forms of resistance to the increase in B chromosome number in the cells have evolved in several species. Indirect evidence for such resistance comes from variable transmission rates for $\mathrm{B}$ chromosomes among individuals within the same population, which suggests a possible influence of A chromosome background on the expression of $\mathrm{B}$ drive. The existence of such intraspecific variability in $\mathrm{B}$ chromosome transmission rates has long been known in species such as rye (Müntzing, 1954), Festuca pratensis (Bosemark, 1954), maize (Carlson, 1969), Myrmeleotettix maculates (Hewitt, 1973), and Hypochoeris maculate (Parker et al., 1982).

Many attempts to estimate the effects of chromosomes on fitness have been made (Jones and Rees, 1982; Shaw and Hewitt 1990; Beukeboom, 1994). In most organisms, B chromosomes are considered as selfish genomic elements. One of the exceptions known so far is found in the chive Allium schoenoprasum, in which seeds carrying even a small number of B chromosomes survive to seedling better than those lacking them (Holmes and Bougourd, 1989) and there was no evidence of $B$ chromosome drive in this species (Bougourd and Parker, 1979). Among Neotropical fish species that present supernumerary chromosomes, no evidence was found supporting the occurrence of adaptive effects due to the extra elements (Carvalho et al., 2008).

There is a wide variety of accumulation mechanisms in which $\mathrm{B}$ chromosomes can assure their maintenance in natural populations (Jones, 1991). One is the mitotic instability of B chromosomes coupled with preferential destiny of cells with higher B number towards the germ line. This mechanism was proposed by Nur (1969) for B chromosomes in several grasshopper species, and has been analyzed in detail in the locust Locusta migratoria (Nur, 1969; Kayano, 1971; Pardo et al., 1995).

Aiming at understanding B chromosome transmission and maintenance patterns, several studies have been conducted. Jones and Rees (1982) showed that in two species rye from the Lago di Garlate, the offspring had more B chromosomes than their parents, indicating a net increase in the frequency within the population. However, the frequency of B chromosomes in parents might have been underestimated because of mitotic instability, as B chromosomes can be lost from somatic tissue but still be present in the germ line. Such mitotically unstable B chromosomes were found in grasshoppers (Rothfels, 1950; Nur, 1969; Kayano, 1971; Pardo et al., 1994) and Polycelis tenuis (Melander, 1950).

The analysis of the nucleolar organizer regions (NORs) location confirmed the findings of Maistro et al. (2000), who described labeling on the long arm of the third chromosome pair, besides a frequent NOR size polymorphism. Jesus and Moreira-Filho (2003) detected one or two additional inactive small sites in another sample analyzed, and Vicari et al. (2006) identified a NOR near the centromere in the interstitial region of the long arm of the fourth chromosome pair. In this work, all the individuals pre- 
sented a NOR marking on the third submetacentric chromosome pair and no additional ribosomal site was found.

The pattern of constitutive heterochromatin in $P$. lineatus was described by Maistro et al. (2000) as generally located in the centromeric region of the chromosomes in the A complement of this species, but the presence of constitutive heterochromatin in the telomeric regions was also observed. In the present work, heterochromatic blocks were identified in the centromeric regions of all chromosomes, and only one chromosome pair presented heterochromatin in the telomeric region. All B chromosomes were found to be completely heterochromatic, confirming data previously described for this species. The increase in the number of $B$ chromosomes in $P$. lineatus does not appear to have any effect on their heterochromatic nature. By contrast, Artoni et al. (2006) observed a small negative C-band segment in the pericentromeric region of a metacentric $\mathrm{B}$ chromosome.

Our results showed that, through induced and controlled reproduction, it is possible to alter the frequency of B chromosomes in $P$. lineatus, thus opening the question as to which would be the maximum number of $\mathrm{B}$ chromosomes that such a species is able to carry in its genome without becoming a burden. Irrespective of the increase in number, no active genes were found located on B chromosomes in this species, and apparently the increase in heterochromatin in the genome does not seem to affect any cell functions.

\section{Acknowledgments}

The authors are grateful to Renato Devidé for technical support, and to Fundação de Amparo à Pesquisa do Estado de São Paulo (FAPESP) and Coordenação de Aperfeiçoamento de Pessoal de Nível Superior (CAPES) for financial support.

\section{References}

Artoni RF, vicari MR, Endler AL, Cavallaro zi, Jesus cm, Almeida mc, Moreira-Filho O and Bertollo LAC (2006) Banding pattern of $\mathrm{A}$ and $\mathrm{B}$ chromosome of Prochilodus lineatus (Characiformes, Prochilodontidae), with comments on B chromosome evolution. Genetica 127:277-284.

Beukeboom LW (1994) Bewildering Bs: An impression of the 1st B-chromosome Conference. Heredity 73:328-336.

Britski Ha (1972) Peixes de água doce do estado de São Paulo. Sistemática 36:79-108.

Bosemark NO (1954) On accessory chromosomes in Festuca pratensis. II. Inheritance of the standard type of accessory chromosome. Hereditas 40:425-437.

Bougourd SM and Parker JS (1979) The B-chromosome system of Allium shoenoprassum. Chromosoma 75:369-383.

Camacho JPM, Sharbel TF and Beukeboom LW (2000) B-chromosome evolution. Phil Trans R Soc London 355:163-178.

Carlson W (1969) Factors affecting preferential fertilization in maize. Genetics 62:638-639.
Carvalho RA, Martins-Santos IC and Dias AL (2008) B chromosomes: An update about their occurrence in freshwater Neotropical fishes (Teleostei). J Fish Biol 72:1907-1932.

Castro RMC (1993) Prochilodus britskii, a new species of Prochilodontide Fish (Ostariophysi, Characiformes) from the rio Apiacá, river Tapajós system, Mato Grosso, Brazil. Proc Biol Soc Wash 106:57-62.

Cavallaro ZI, Bertollo LAC, Perfectti F and Camacho JPM (2000) Frequency increase and mitotic stabilization of a B chromosome in fish Prochilodus lineatus. Chromosome Res 8:627634.

Fenocchio AS, Pastori MC, Roncati HA, Moreira-Filho O and Bertollo LAC (2003) A cytogenetic survey of the fish fauna from Argentina. Caryologia 56:197-204.

Foresti F, Oliveira C and Almeida-Toledo LF (1993) A method for chromosome preparations from large specimens of fishes using in vitro short treatment with colchicine. Experientia 49:810-813

Godoy MP (1975) Peixes do Brasil: Sub-ordem Characoidei. Editora Franciscana, Piracicaba, pp 629-847.

Goulding M (1981) Man and fisheries on an Amazon frontier. Kluwer Academic Publishers, 137 pp.

Hewitt GM (1973) Variable transmission rates of a B chromosome in Myrmeleotettix maculatus (Thunb.). Chromosoma 40:83-106.

Holmes DS and Bougourd SM (1989) The B chromosome selection in Allium shoenoprasum. I. Natural population. Heredity 63:83-87.

Howell WM and Black DA (1980) Controlled silver-staining of nucleolus organizer regions with a protective colloidal developer: A 1-step method. Experientia 36:1014-1015.

Jesus CM and Moreira-Filho O (2003) Chromosomal localization of $5 \mathrm{~S}$ and $18 \mathrm{~S}$ rRNA genes in Prochilodus lineatus (Characiformes, Prochilodontidae). Caryologia 56:281-287.

Jones RN (1991) B-Chromosome drive. Am Nat 137:430-442.

Jones RN (1995) Tansley review no. 85: B chromosomes in plants. New Phytol Trust 131:411-434.

Jones RN and Rees H (1982) B Chromosomes. Academic Press, New York, 266 pp.

Kayano H (1971) Accumulation of B chromosomes in the germline of Locusta migratoria. Heredity 27:119-1123.

Lowe-McConell R (1975) Fish communities in tropical freshwaters. Longman, New York, 337 pp.

Maistro LM, Oliveira C and Foresti F (2000) Cytogenetic analysis of A and B chromosomes of Prochilodus lineatus (Teleostei, Prochilodontidae) using different restriction enzyme banding and staining methods. Genetica 108:119-125.

Melander Y (1950) Accessory chromosomes in animals especially in Polycelis tenuis. Hereditas 36:19-38.

Müntzing AS (1954) Cytogenetics of accessory chromosomes (B-chromosomes). Caryologia 6:282-301.

Nur U (1969) Mitotic instability leading to an acumulation of B-chromosomes in grasshoppers. Chromosoma 27:1-19.

Oliveira C, Saboya SMR, Foresti F, Senhorini JA and Bernardino G (1997) Increased B chromosome frequency and absence of drive in the fish Prochilodus lineatus. Heredity 79:473476.

Pardo MC, López-León MD, Cabrero J and Camacho JPM (1994) Transmission analysis of mitotically unstable B chromosomes in Locusta migratoria. Genome 37:1027-1034. 
Pardo MC, López-León MD, Hewitt GM and Camacho JPM (1995) Female fitness is increased by frequent mating in grasshoppers. Heredity 74:654-660.

Parker JS, Taylor S and Ainsworth CC (1982) The chromosome system of Hypochoeris maculata. III. Variation in B-chromosome transmission rates. Chromosoma 84:229-310.

Pauls E and Bertollo LAC (1983) Evidence for a system of supranumerary chromosomes in Prochilodus scrofa Steindacher 1881 (Pisces Prochilodontidae). Caryologia 36:307-314.

Pauls E and Bertollo LAC (1990) Distribution of a supranumerary chromosome system and aspects of caryotipic evolution in the genus Prochilodus (Pisces, Prochilodontidae). Genetica 8:117-123.

Puertas MJ (2002) Nature and evolution of chromosome in plants: A non-cod but information-rich part of plant genomes. Cytogenet Genome Res 96:198-205.

Rothfels KH (1950) Chromosome complement, polyploidy and supernumeraries in Neopodismopsis abdominalis. Chromosomes Today 1:28-30.

Shaw MW and Hewitt GM (1990) B chromosomes, selfish DNA and theoretical models: Where next? In: Futuyma D and
Antonovics J (eds) Oxford Surveys in Evolutionary Biology. Oxford University Press, Oxford, pp 197-223.

Sumner AT (1972) Chromosome Banding. Unwin Hyman Inc., Cambridge, $434 \mathrm{pp}$.

Vari RP (1983) Phylogenetic relationships of the families Curimatidae, Prochilodontidae, Anostomidae and Chilodontidae (Pisces, Characiformes). Smithsonian Contributions to Zoology. Smithsonian Institution Press, Washington, $378 \mathrm{pp}$.

Vicari MR, Almeida MC, Bertollo LAC, Moreira-Filho Oand Artoni RF (2006) Cytogenetic analysis and chromosomal characteristics of the polymorphic $18 \mathrm{~S}$ rDNA in the fish Prochilodus lineatus (Characiformes Prochilodontidae). Genet Mol Biol 29:621-625.

Voltolin TA, Senhorini JA, Oliveira C, Foresti F, Bortolozzi J and Porto-Foresti F (2009) Utilization of cytogenetic markers in wild population of curimbatá (Prochilodus lineatus) from Mogi-Guaçu River. Cytologia 74:281-287.

Wilson EB (1907) The supernumerary chromosomes of Hemiptera. Science 26:870-871.

Associate Editor: Yatiyo Yonenaga-Yassuda

License information: This is an open-access article distributed under the terms of the Creative Commons Attribution License, which permits unrestricted use, distribution, and reproduction in any medium, provided the original work is properly cited. 